to a Careers Workshop during their placement and surveyed before $(n=20)$ and after $(n=13)$ (Intervention Group). The workshop covered the 'highs' and 'lows' of working in Paediatrics as well as general careers advice, and a separate survey was completed to evaluate this $(n=18)$.

Results Paediatrics was a popular 'Top 3' careers option, second only to General Practice. Students reported that formal careers advice and clinical contact are both important for career planning. Positive perceptions of Paediatrics included working with children, clinical variety and being rewarding. Negative perceptions focused on emotional challenges, poor work-life balance and managing parents. After placement, the Intervention group were more likely to comment on the positive aspects of a 'clinically varied' and 'rewarding' workload.

Following the Careers Workshop, $72 \%$ of students felt 'well informed' about careers in medicine generally and 94\% regarding careers in Paediatrics. The workshop helped to address pre-conceptions regarding competition ratios and work-life balance.

In both groups, students were more likely to consider Paediatric training following their placement, with interest increasing from 69\% to $76 \%$ (Standard group) and $70 \%$ to 77\% (Intervention group).

Conclusion Our data demonstrates that clinical placements influence students' perceptions of a specialty. Although the Careers Workshop improved knowledge of careers in Paediatrics, there was no measurable difference between groups in the overall number of students considering the specialty. Nevertheless, trainees and consultants should be aware of the importance of clinical placements in shaping students' understanding and perceptions of a specialty. Careers advice should be integrated throughout the medical school curriculum and could run alongside clinical placements rather than as a separate entity.

\section{G199(P) AN INNOVATIVE APPROACH TO INTER-PROFESSIONAL PAEDIATRIC SIMULATION TRAINING: A FACILITATED 'HOPES AND CONCERNS' CONVERSATION TO ENHANCE PSYCHOLOGICAL SAFETY}

A Kilonback, B Desai. Paediatric Simulation, Epsom General Hospital, Epsom, UK

\subsection{6/archdischild-2020-rcpch. 168}

Background Providing a safe and positive environment for learners within simulation is crucial, this need is often amplified with an inter-professional learner group on a mandatory course.

Aims Create a safe space to allow open and honest discourse to promote effective inter-professional learning through simulation.

Methods Staff from nursing and medical backgrounds were allocated time to attend the training day by their rota coordinators. Each training day commenced with a facilitated 'hopes and concerns' session. The participants wrote down their hopes and concerns regarding the simulation training day. These were collated by the facilitator who identified common themes and developed them through discussion with the group to promote psychological safety and formulate tailored learning objectives and ground rules.

Participants completed pre and post course questionnaires and a focus group of faculty and learners was used to evaluate the effect.

Results The course was run on 16 separate days and was delivered to 137 learners representing a range of healthcare professionals including healthcare assistants, nurses, physician's associates and a variety of doctors from FY2 to consultants.

All participants reported an improvement in their technical and non-technical skills and there were spontaneous recommendations from the participants that more paediatric training should be multi-professional.

Allowing time to reflect on hopes and concerns and write them down enabled the facilitator to draw out comments from both the extroverts and introverts in the group. Common themes with regard to hopes included developing technical and non-technical skills. Common themes with regard to concerns were feeling stressed, nervous, embarrassed, being judged and intimidated. These themes were shared across professions and levels of seniority.

Faculty members remarked that the new introduction 'improved engagement and participation in the debrief'. Learners commented that the introduction 'levelled the playing field' and in the debrief they felt 'safe to discuss their own feelings, previous experiences and mistakes'. Some additional comments from the post-course questionnaire included 'great team support', 'empowering day', 'extremely non-judgmental' and 'made to feel comfortable.'

Conclusions Inter-professional simulation training with a hopes and concerns facilitated discussion improves leaners engagement with simulation training leading to development of confidence and skills.

\section{G200(P) PROJECT POSITIVITY}

${ }^{1} \mathrm{MS}$ Mooncey, ${ }^{2} \mathrm{C}$ Bestwick, ${ }^{2,3} \mathrm{JP}$ Dilworth, ${ }^{2} \mathrm{R}$ Heath, ${ }^{4} \mathrm{~S}$ Laurent, ${ }^{3} \mathrm{~A}$ Pervez, ${ }^{2} \mathrm{~S}$ Sabale, ${ }^{1} E$ Bond. 'Paediatrics and Child Health, The Royal Free Hospital, London, UK; ${ }^{2}$ Medical School, UCL, London, UK; ${ }^{3}$ Medical Education, The Royal Free Hospital, London, UK; ${ }^{4}$ Paediatrics and Child Health, Barnet Hospital, London, UK

10.1136/archdischild-2020-rcpch. 169

'Positivity breeds positivity'. However. Medical students report feeling 'shunned' or 'ignored whilst on clinical placement. Morale for members of staff across the NHS is low. Why are we always so quick to talk about when things go badly, but we very rarely discuss and celebrate things going well?

Aims

- To improve medical student integration as part of the clinical team

- To increase the focus on positivity within the workplace, for all members of the MDT

Methods We created 'InteGreat' - a project focused on improving integration of medical students into the clinical team, (through the use of prompt cards and induction sessions). This was launched at our lunchtime event entitled 'Positivity in Paediatrics', which all members of the MDT were welcomed to. This was a platform for the introduction of new positive initiatives, and a celebration of the existing positive work in the department.

In combination with a 'Team Lunch' (and lots of baked goods!) a fantastically positive environment was created. A wellbeing questionnaire was distributed at the start and end of the session, to assess value and enjoyment of the session.

Results The session was extremely well received. $72 \%$ of people 'Strongly agreed' that the session was useful and $100 \%$ of participants 'Strongly agreed' that the session was enjoyable. The session received particularly glowing feedback from the 